\title{
Article
}

\section{Identifying the key components of a 'whole family' intervention for families experiencing domestic violence and abuse}

Stanley, Nicky and Humphreys, Cathy

Available at http://clok.uclan.ac.uk/18558/

Stanley, Nicky ORCID: 0000-0002-7644-1625 and Humphreys, Cathy (2017) Identifying the key components of a 'whole family' intervention for families experiencing domestic violence and abuse. Journal of Gender-Based Violence, 1. pp. 99-115. ISSN 2398-6808

It is advisable to refer to the publisher's version if you intend to cite from the work. http://dx.doi.org/10.1332/239868017X14913081639164

For more information about UCLan's research in this area go to http://www.uclan.ac.uk/researchgroups/ and search for <name of research Group>.

For information about Research generally at UCLan please go to http://www.uclan.ac.uk/research/

All outputs in CLoK are protected by Intellectual Property Rights law, including Copyright law. Copyright, IPR and Moral Rights for the works on this site are retained by the individual authors and/or other copyright owners. Terms and conditions for use of this material are defined in the policies page. 


\section{Journal of Gender-Based Violence Identifying the Key Components of a 'Whole Family' Intervention for Families Experiencing Domestic Violence and Abuse \\ --Manuscript Draft--}

\begin{tabular}{|c|c|}
\hline Manuscript Number: & JGBV-D-17-00011R1 \\
\hline Article Type: & Academic article \\
\hline Full Title: & $\begin{array}{l}\text { Identifying the Key Components of a 'Whole Family' Intervention for Families } \\
\text { Experiencing Domestic Violence and Abuse }\end{array}$ \\
\hline First Author: & Nicky Stanley \\
\hline Corresponding Author: & $\begin{array}{l}\text { Nicky Stanley } \\
\text { University of Central Lancashire School of Social Work Care and Community } \\
\text { Preston, UNITED KINGDOM }\end{array}$ \\
\hline \multicolumn{2}{|l|}{$\begin{array}{l}\text { Corresponding Author Secondary } \\
\text { Information: }\end{array}$} \\
\hline Corresponding Author E-Mail: & nstanley@uclan.ac.uk \\
\hline Other Authors: & Cathy Humphreys \\
\hline Abstract: & $\begin{array}{l}\text { 'Whole family' interventions for families living with domestic violence and abuse (DVA) } \\
\text { are emerging and some international practice examples are available. This study } \\
\text { reports a process evaluation of a pilot delivered in Northern England that aimed to } \\
\text { work with all members of families experiencing DVA. The evaluation involved analysis } \\
\text { of detailed accounts of practice from learning logs and case workbooks as well as } \\
\text { interviews with practitioners and family members. } \\
\text { The voluntary nature of families' involvement with the pilot, together with an explicit } \\
\text { service philosophy of 'meeting families where they are at' appeared successful in } \\
\text { engaging families. Pilot staff worked flexibly, seeing family members together and } \\
\text { separately, but there was evidence of lower levels of confidence in work with } \\
\text { perpetrators. } \\
\text { Co-work enabled skills to be transferred to other professionals and social workers } \\
\text { increased their use of risk assessment tools in DVA cases. However, there was } \\
\text { uncertainty as to whether interagency communication improved across local agencies } \\
\text { and joint protocols and tools were slow to develop. This study is one of the first } \\
\text { evaluations of 'whole family' interventions in DVA and it illustrates how, when additional } \\
\text { resources and organisational support are made available, a non-blaming approach } \\
\text { which families find engaging can be developed. }\end{array}$ \\
\hline Keywords: & $\begin{array}{l}\text { 'whole family approach', domestic violence and abuse, mothers, fathers, children, } \\
\text { parenting }\end{array}$ \\
\hline \multicolumn{2}{|l|}{ Additional Information: } \\
\hline Question & Response \\
\hline $\begin{array}{l}\text { Key Messages } \\
\text { Please enter } 2-3 \text { single sentence bullet } \\
\text { points describing the key messages of the } \\
\text { paper. }\end{array}$ & $\begin{array}{l}\text { - There are some practice examples but few evaluations of 'whole family' approaches in } \\
\text { domestic violence. } \\
\text {-Working on a voluntary basis and 'starting where they were at' appeared successful in } \\
\text { engaging families with a 'whole family' pilot. } \\
\text {-Family members were seen together and separately, but staff had less confidence in } \\
\text { work with perpetrators. }\end{array}$ \\
\hline $\begin{array}{l}\text { Word Count } \\
\text { Academic articles should be between } \\
5000 \text { and } 7000 \text { words in length. } \\
\text { Policy and Practice articles should be }\end{array}$ & 7000 \\
\hline
\end{tabular}


between 2000 and 4000 words in length.

Open Space pieces should be between should be between 2000 and 4000 words in length.

\section{Special issue}

Is this a submission for a special issue? If so please give details of the special issue, including the Editor if known.

\begin{tabular}{|c|c|}
\hline Funding Information: & Department for Education \\
\hline Manuscript Classifications: & Age; Domestic violence/abuse; Social Work \\
\hline Manuscript Region of Origin: & UNITED KINGDOM \\
\hline Author Comments: & $\begin{array}{l}\text { We have revised and resubmitted this paper speedily as requested, focusing on the } \\
\text { two key issues identified in the Editor's letter. Details of the amendments are provided } \\
\text { in the response to reviewers. } \\
\text { Nicky Stanley }\end{array}$ \\
\hline Response to Reviewers: & $\begin{array}{l}\text { In revising the paper, we have focused on the two key points made by the Editor: } \\
\text { 1.To outline and make clearer towards the beginning of the article what the model is } \\
\text { that you are evaluating/ proposing } \\
\text { We have added a section to the end of the first paragraph of the paper describing the } \\
\text { intervention in more detail. } \\
\text { 2.To discuss more explicitly, and from earlier in the article, that there may be issues } \\
\text { regarding DVA severity and risk that need to be considered before applying the } \\
\text { different models you outline in the overview. } \\
\text { We have strengthened the discussion of the risks of 'whole family' approaches in the } \\
\text { penultimate paragraph on page } 2 \text { by emphasising the danger that victims may be } \\
\text { encouraged to remain in high risk situations by the approach. On page } 3 \text {, we have } \\
\text { included the point that the Oranje Huis's 'whole family' work excludes perpetrators } \\
\text { assessed as high risk. } \\
\text { We have also checked and updated all references and included references to the } \\
\text { authors' own publications as well as adding an Acknowledgement. } \\
\text { In resubmitting the paper, we have acknowledged the funding source which was } \\
\text { previously omitted. } \\
\text { Nicky Stanley and Cathy Humphreys }\end{array}$ \\
\hline
\end{tabular}



Domestic Violence and Abuse

'Whole family' approaches to domestic violence and abuse (DVA) are beginning to emerge in the UK, Australia and elsewhere. These approaches take varying forms but are linked by the common aim of engaging with all family members - mothers, fathers/father figure and children - in families living with domestic violence. They seemingly challenge the traditional focus of DVA interventions which originally adopted an exclusive focus on women as victims and later expanded their remit to include children living with DVA with perpetrator programmes developing in a separate stream alongside them. To date, evidence for the effectiveness of 'whole family' interventions has been lacking. This paper begins by outlining the shifts in knowledge and practice that have fuelled the development of these new approaches and proceeds to identify some practice examples that illustrate the range of models found under the international umbrella of 'whole family' interventions in DVA. These accounts provide the context for the findings of a study evaluating a 'whole family' DVA service piloted in one town in Northern England over 18 months. This intervention was delivered by a team of trained and well supported specialist DVA workers who worked with individual family members as well as seeing family members together. They offered a flexible service that aimed to engage with families on their own terms, regardless of whether they wished to remain together or whether they had separated or planned to do so. Increasing the safety and wellbeing of children as well as that of victims were core objectives and the pilot also aimed to build expertise and confidence in DVA work with families among other local practitioners. To the authors' knowledge, this study represents the first European evaluation of this type of 'whole family' intervention.

The roots of whole family approaches spring from a number of different sectors. In the UK, Australia and North America, child protection social work has increased its capacity to identify DVA and its impact on children (Kimball, 2016). In England and Wales, DVA was the factor most frequently identified by children in need assessments in 2016 with DVA being identified in $49.6 \%$ of all such assessments (DfE 2016). However, child protection social work has attracted substantial criticism for its exclusive focus on the mothers of children living with DVA. As a consequence of the failure to engage abusive fathers or partners in child protection social work, mothers have been positioned as responsible for protecting their children from DVA and subsequently blamed when they have been unable to do so (Featherstone and Peckover, 2007; Lapierre, 2010). In this way, mothers have been subjected to the 'double whammy' of DVA and the punitive scrutiny of child protection services (Humphreys and Absler, 2011; Stanley, Miller, Richardson-Foster, and Thomson, 2011). Increasingly, social work has acknowledged the extent to which this approach can alienate families and training initiatives and co-location schemes have been introduced to develop its practitioners' skills and capacity to engage with abusive fathers (see Maxwell et al 2012; Blacklock and Phillips 2015).

An expanding recognition of the need to address and change the behaviour of abusive men has resulted in the increase of perpetrator programmes and a concomitant growth of confidence and expertise in working with DVA perpetrators. Child protection services are increasingly viewing community based perpetrator programmes as a means of delivering interventions to abusive fathers (Humphreys and Stanley 2017). Kelly and Westmarland's (2015) UK evaluation noted that over twothirds of referrals to such programmes came from children's social services or from CAFCASS which provides representation of children's needs in child protection court proceedings. As these community based perpetrator programmes have proliferated, it has become increasingly clear that 
many men who are violent and abusive towards their partners are also fathers and evidence concerning the quality of their fathering is slowly accumulating (Bancroft and Silverman 2011; Holt 2015; Heward-Belle, 2016). This recognition is underpinned by a trend for generic parenting programmes to target fathering as well as mothering (Scourfield, Cheung, and Macdonald, 2014), and this shift reflects a broader turn towards examining fathers and fatherhood (Lamb 2010; Featherstone 2009).

In tandem with other services, the independent domestic abuse sector has also begun to acknowledge the reluctance of some DVA victims to separate from abusive partners (Humphreys and Campo, 2017 forthcoming). Separation is recognised as risky in itself and the accounts of women who have struggled with isolation, limited resources and continued violence to build independent lives post-separation have contributed to the recognition that separation may not be the answer for all victims (Stanley, 2011). Moreover, for those women who have separated, child contact can provide a setting in which DVA can be perpetuated and assume new forms (Radford and Hester, 2015).

Whole family DVA approaches also chime with other 'whole family' interventions. Proponents of family group conferences (FGCs) have long argued for their wider use (Morris and Connolly, 2012) and there has been some development of practice specific to families living with DVA (Pennell and Burford, 2002). In the UK, Family Intervention Projects (FIPs) and their successor, the Troubled Families programme, have aimed to engage all family members in the addressing a range of behaviours and the remit of the Troubled Families programme was expanded in 2014 to include families experiencing DVA (https://www.gov.uk/government/news/troubled-familiesprogrammeme-expanded-to-help-younger-children).

However, the use of 'whole family' approaches in the field of DVA has evoked some concerns. In particular, there is the possibility that such approaches fail to acknowledge the gendered nature of DVA and the very different positions of different family members who live with DVA (Stanley, 2015). Commentators have highlighted the risks that information shared in 'whole family' sessions or across sessions may expose victims and children to further abuse or that the sessions themselves may become sites of control and coercion (Kohn 2010; Humphreys and Campo, 2017 forthcoming). Research on couple counselling where there is DVA identifies the potential for retaliation and escalation of abuse (Simpson, Gattis, Atkins \& Christensen, 2008; Jory et al, 1997) and the inappropriateness of delivering this type of intervention when one partner is fearful of the other or when the perpetrator takes no responsibility for the violence has been emphasised (Jenkins, 2009). If risks are hidden or poorly assessed, victims may feel encouraged to remain in dangerous situations: there is evidence from domestic homicide reviews that both victims and professionals can be over-optimistic in their assessments of safety (see for instance, Barry, 2011). There is also the distinct possibility that a combination of the practitioner's struggles to maintain an even-handed perspective on the conflicting needs and accounts of all family members, together with men's resistance to and evasion of DVA interventions may result in women and children becoming the focus of these approaches by default.

\section{Models of 'Whole Family' Practice}

Developments in DVA 'whole family' approaches reflect diverse perspectives and emphases depending upon the service sector in which they are situated. Health visitors, infant mental health specialists, the refuge sector, family services and children's social care provide programmes with both differences and commonalities (Humphreys and Campo, forthcoming 2017). At this stage, the 
evaluation base is relatively weak, though some studies are showing evidence of change relative to control groups (Kan and Feinberg, 2014; Stover, 2015; Mejdoubi et al, 2013).

A number of programmes highlight intervention early in the life course with a focus on mothering and fathering with infants and under five year olds, though the programme areas from which they spring are diverse (Mejdoubi et al, 2013; Kan \& Feinberg, 2014; Stover, 2013; Stefanou Foundation; 2015). While health visitors acknowledge the problems of home visiting where there is DVA (Sharps, Campbell, Baty, and Bair-Merrit, 2008), their practice continues to focus primarily on the motherchild relationship. An exception lies with a programme in the Netherlands which worked with 460 disadvantaged families (Mejdoubi et al, 2013). The intervention actively involved both parents in discussing DVA, supporting partners with strategies for emotional regulation and communication, and helping both partners make safer decisions to prevent the escalation of arguments to physical violence.

The Healthy Relationships, Healthy Baby programme (Sephanou Foundation, 2015) is currently being trialled in two sites in England. The independently funded teams are located in local authority children's social care with referrals coming primarily from this source. This early intervention pilot works with mothers and fathers from pregnancy onwards with the aim of preventing the impact of DVA on infants. Parents who meet specified criteria following individual risk assessments are invited to attend a programme aimed at supporting their parenting from pregnancy through to year two. Most sessions are directed at men and women separately. Couple work may occur after extensive individual work has established a context of no violence. Evaluation is at an early stage.

Several different interventions have been or are being trialled in the US. The Family Foundations programme (Kan and Feinberg, 2014) engages with vulnerable families in the transition to parenthood. Eight sessions are provided to couples in a group work model of psycho-education with four sessions provided prior to the birth of the baby and four sessions in the perinatal period. A trial involving 169 couples showed significant effects in reduced partner psychological aggression by fathers and reduced parent-child physical aggression by mothers relative to the control group. In the same vein of intervening early in the lifecourse, the Fathers for Change programme developed by Stover (2015) and her colleagues draws from the area of child trauma and infant mental health. Working with highly trained, multi-lingual, DVA and infant mental health specialists, a 16 week, 16 topic programme of intervention is provided. It comprises three stages: individual work with fathers, co-parenting, and father-child sessions if sufficient progress has been made for these final sessions to be safe for the infant.

Other 'whole family' interventions have taken a different focus. For instance, the Oranje Huis (Orange House) in the Netherlands grew out of work in the refuge sector (Blijf Groep, 2011). While women are living in the refuge and, following a risk assessment to exclude perpetrators of severe violence, her partner or ex-partner is offered a service from the refuge as well. While there is security at the refuge, the address is not secret. Sessions are individual as well as couple based with a major focus on parenting. Children at the refuge are also provided with support. Service data showed work was undertaken with partners in $40 \%$ of cases (Blijf Groep, 2011).

In both the UK and Australia, there are a number of other programmes which have developed from the specialist family services sector who work with families in need where there is DVA, though all appear to be at early stage of evaluation. Examples lie with the Daybreak Dove programme in South England (see Author 2011), Family Group Conferences specialising in DVA (Leeds City Council undated), and Jannawi Family Services (Jannawi Family Centre, 2015). 
There are both similarities and differences in these approaches which, instead of gender specific programmes for men and women, at times work with men and women together in spite of the experiences of DVA. Interventions vary in the extent to which they provide direct work with children. Where children are infants, work is likely to focus on the parents. All programmes emphasise the need for worker training and supervision in DVA as well as other specialist areas (e.g. child development). Most undertake separate work with men, women and children and usually when working with men and women together focus on co-parenting issues rather than the couple. In this sense, 'whole family' approaches do not imply extensive family therapy, but rather work with different members of the family both separately and together. There is no assumption that all families are suitable for this approach. Extensive individual risk and safety assessments are undertaken to exclude men: with little potential to change due to substance use and mental health problems; are currently not ready to take responsibility for change; or who would be too dangerous for their partners, their children or workers (Humphreys and Campo, 2017 forthcoming).

In short, the literature and practice examples acknowledge that there are significant risks associated with 'whole family' approaches. The vulnerability of women and children where there is violence and a significant power differential are not to be under-estimated. Nevertheless, for those women and children who are not in a position to separate where there is DVA and for those where there will continue to be ongoing contact post-separation, work is developing to respond to their needs and to engage with fathers who use violence who are motivated to change.

\section{The Growing Futures Intervention}

Growing Futures, the whole family intervention described here, was implemented in Doncaster, North England, between 2014 and 2016. Funding was provided by the Department for Education's Innovations programme which supported the pilot project for its first 18 months. Doncaster is unusual in the UK in that children's social services are not managed directly by the local authority. In 2014, Doncaster Children's Services Trust (DCST) was established to take over the management of children's social services whose standards were judged by Government as 'inadequate'. A combination of serious case reviews and negative inspections had contributed to this assessment but Doncaster is also a city characterised by high levels of unemployment and deprivation following the decline of heavy industry in the region. Those responsible for the implementation of the intervention described a local history of difficulties in multi-agency work and a lack of trust between the local population and statutory services as part of the rationale for the new service.

The Growing Futures project was conceived and delivered by DCST with a Board established at an early stage to oversee both strategic and operational matters. The team consisted of 12 Domestic Abuse Navigators (DANs), eight of whom were experienced practitioners recruited specifically to the pilot project who came from a range of professional backgrounds. Four came from children's social work or family support, one had a background in Early Years work, two came from the DVA sector, while the remaining DANs had backgrounds in Youth Justice, Drugs and Alcohol services, Forensic Mental Health services and counselling work. Two specialist perpetrator workers were employed by the project: one worked in the DAN team and was tasked with engaging with male perpetrators and linking them to the local perpetrators programme, while the other worked in police custody settings. In addition, two specialist drug and alcohol practitioners were recruited to the team which also included four social workers already employed by the Trust who were to work part-time as DANs. The team was completed by two senior DANs responsible for undertaking supervision and a team manager. Most of the Growing Futures practitioners were women although two of the part-time social workers were male and both the perpetrator workers were men. The team was provided with 
high levels of supervision and support and a range of training inputs including specialist domestic abuse training.

The DANs were co-located in offices alongside DCST social workers or based in children's centres. Their caseloads were restricted to 12 families and no more than 20 children. This compared positively to the caseloads of DCST child care social workers who reported working with caseloads of around 30 children. Flexibility of service was ensured by the absence of any time limit on the length of intervention with a family.

The intervention aimed to harness a whole family approach in order to reduce the emotional harm that DVA inflicted on children and young people. While the recovery of victims and the reduction of repeat victimisation were also stated aims, the safety and wellbeing of children was the core objective as the project's location in the Children's Trust indicates. 'Whole system' change was another project aspiration with stated aims including challenging the acceptance of DVA among families and the wider community and breaking the cycle of DVA in families in Doncaster. Aspects of the intervention designed to achieve these broader goals included training, mentoring and collaborative work with other professionals, a leadership coaching programme for managers of relevant services, the development of a programme addressing child to parent abuse, action research with local young people and the development of a new DVA strategy for Doncaster.

\section{Methods}

The multi-method evaluation of the Growing Futures intervention was undertaken in 2015-2016 by Opcit an independent research organisation, with the lead author of this paper collaborating on the study. The time required for project start-up together with the limited time frame of 18 months for the evaluation made for difficulties in implementing reliable outcome measures and this study therefore considers the in-depth process data collected. Detailed accounts of the DANs' work were captured by structured learning logs which they completed at regular intervals over a period of 12 months. The learning logs incorporated headings that required the DANs to describe their achievements and the challenges encountered in their work; their use of professional knowledge and situations where they felt their professional knowledge was lacking as well as instances of interagency collaboration and work. DANs provided consent for their learning logs to be utilised for research purposes. All 12 DANs (including the part-time social worker DANs), the perpetrator worker who was based in the team, the two senior DANs, the DANs' manager and the project manager were interviewed as were four other local professionals who worked regularly with the Growing Futures service. Analysis of all the DANs' case workbooks was undertaken in order to identify DANs' caseloads and case management, as well as assessment and referral practices. Semi-structured interviews were also completed with families who had used the Growing Futures service, including three mothers, two male perpetrators and two children. Informed consent was obtained for all interviews which were recorded and transcribed. Ethical approval was provided by the University of Central Lancashire's Ethics Committee.

Analysis was thematic (Braun and Clarke, 2006) and was informed by key questions including: what aspects of the Growing Futures model enabled it to achieve its objectives, what was the impact on families and what was the impact on other professionals and wider systems? In common with other such evaluations (Hutchfield and Coren, 2011), time restrictions and difficulties in accessing service users made for a limited number of completed interviews with family members. This paper 
therefore focuses on identifying the key characteristics of the model as implemented and explores the impact of the pilot on wider systems and other professionals.

\section{Findings \\ DANs' Conceptions of DVA and of the Growing Futures Service}

DANs, the majority of whom were social work trained, tended to emphasise the role of local social, economic and cultural factors in contributing to high levels of DVA in Doncaster. Gender was occasionally mentioned as a significant issue but high levels of deprivation and normalisation of DVA predominated in their explanations of why the Growing Futures intervention was required:

..there has always been a significant issue with levels of domestic abuse amongst families, generational issues, culturally it's seen as something that's accepted, it's not challenged by people on a daily basis, including professionals...may be due to some of the kind of social economic issues, for example, people having quite traditional jobs, or... working down the pit...have had an impact on upbringing, and attitudes towards women, in particular, children. And the issues are still there... (DAN)

Other DANs highlighted the high prevalence of drug and alcohol problems in the area and described an intergenerational cycle of DVA:

there's a lot of deprivation. There's a lot that's ingrained that abuse is the norm, and it's trying to prevent that cycle repeating itself. There certainly is a lot of financial difficulties. Drugs and alcohol use as well. (DAN)

However, although gender was not a strong theme in the DANs' conceptions of DVA, they were clear that the service aimed to challenge male perpetrators to take responsibility for their behaviour and to avoid the victim blaming that had previously characterised professionals' interactions with families:

I think we need to hold a perpetrator accountable, and when we're talking about, and writing those things in conference reports, and making them actions for the family, we need to be really careful that we're not re-victimising that victim. (DAN)

DANs characterised their service as using a range of pre-designed tools or models to deliver therapeutic approaches with families. Working with all family members was identified as a key feature of the service and the 'whole family' approach was seen to offer dividends in terms of promoting perpetrators' engagement with services. One DAN noted how this differed from established social work practice locally and commented that her previous experience had been that perpetrators tended to minimise the impact of the abuse on their partner but:

'...when it comes to children somehow, in my experience, they really listen to that and it seems to have a big impact. So that's different again, which I feel nobody does so far anywhere in this authority. (DAN)

\section{Engaging with Families}

DANs were explicit in emphasising that client engagement with their service was optional and they, children's social workers and families agreed that the voluntary nature of the Growing Futures 
service, as contrasted with the statutory role of children's social care, facilitated engagement. This woman acknowledged that any important information she disclosed was going to be shared with social services but nevertheless found it easier to disclose in the non-coercive context of a relationship with a DAN:

Sometimes I think it is a bit actually easier to speak to the DANS than it is to the social worker, because you do have that thing because it is social services. If it's something important they're going to find out anyway, but it's just easier to speak to someone else.(Victim)

There were numerous examples in the learning logs of DANs co-working with children's social workers and in some cases there was evidence that they were able to utilise the differing nature of their relationships with a family constructively:

...the DANS they are apart from the social workers so I think in that way they can build a better relationship with the client in terms of therapeutic [work]... Whereas if they're doing it with the social worker they might have all these barriers up because well this is the social worker and she wants to take my kids and I'm not saying anything type thing. So in that way I think the DANS and social workers work really well. (Social Worker)

The Growing Futures philosophy advocated a flexible approach that entailed 'meeting families where they are at' and a willingness to work with families who wished to stay together also appeared to promote engagement for some families:

when she said 'I work to keep families together.' That's what turned it for me, because obviously me and [...] didn't want to give up on being in a relationship and being a family.' (Victim)

However, not all families felt like this. For instance, some victims were unwilling to have the same practitioner seeing both them and their partner/ former partner and where this was the case, this was respected. In other families, the DAN's role was centred on assisting separated couples to develop plans for safe contact and shared care of children.

\section{Who Worked with Who?}

Table 1 presents data from DANs' case workbooks that shows the extent of the DANs' involvement with different family members in the first 18 months of the pilot. The definition of 'direct work' as opposed to simply being part of the allocated caseload is the DANs' own but it is clear that mothers and children were the two groups most likely to be worked with directly while direct work with perpetrators was undertaken with just over half the perpetrators on the DANs' caseloads.

\section{Insert Table 1 here.}

The perpetrators, of whom all but two were male, were likely to be worked with separately by the male Growing Futures perpetrator worker: 44 of the 49 perpetrators described as engaged with the service were referred to this worker in the first 18 months of the pilot. However, they might also be involved in some joint sessions with their partner which were delivered by one of the other DANs. Twenty referrals were made by the Growing Futures team to the local perpetrator programme in the course of the pilot. Another feature of the intervention was the work undertaken with perpetrators in the local prison. 
However, work with perpetrators stood out as the area where some of the DANs (not the specialist perpetrator workers) continued to lack confidence and looked to other organisations to undertake the work:

'... when I talked to him about what our service could offer him in terms of direct work I felt very unconfident ...I did however offer him support via group work which is run by another service' (DAN)

DANs worked with family members together, separately and also jointly with other practitioners - at times, separate workers worked with different family members. Children were sometimes seen in sibling groups at home or at school and sometimes with their mothers. DANs reported using joint sessions to improve and repair mother-child communication on the issue of DVA:

'...the children and the adults don't talk to each other about it [DVA]. It becomes this monster, this elephant in the room. So when we get to the point where they can talk about it, then I can facilitate that with, sometimes, the pictures or the drawing, or whatever, to say, 'Come on, let's talk about it together', so that the mother hears as well, rather than me telling her.' (DAN)

There were no references in the learning logs to seeing children with their fathers without mothers present or to working on fathers' parenting without the involvement of mothers. One DAN identified a need for a parallel group intervention for fathers and children that would take a similar form to groupwork undertaken with children and mothers, stressing the need for any such intervention to assess and manage potential risks. However, no such intervention was under development at the time of interview.

\section{Intervention Content}

DANs were encouraged and expected to draw on a wide tool-box of techniques and approaches and their training and supervision were aimed at promoting a range of skills. Much of the work undertaken with mothers involved DANs advocating on behalf of women with other services and attempting to repair communication between mothers and other practitioners:

Mother was frustrated about the inconsistency of agency participation... Using solution focused brief therapy, [we] formulated a plan... of how she would like to be supported in these difficult meetings by key agencies...' (DAN)

'I explained to a school teacher how mum's lack of willingness to implement bedtime routines was possibly not just due to poor parenting but also to mum's self esteem that might have been damaged by the recent domestic abuse' (DAN)

Work with mothers on building parenting skills was also evident in the accounts provided in the DANs' learning logs:

'looked at different ways the Mother manages parenting challenges with her son who has Aspergers... and...is beginning to act aggressively. With further exploration, using the DASH I was able to reflect some patterns of using a token economy, and also considering some sensory adaptations' (DAN) 
Interviews with DANs yielded accounts of them undertaking joint work on parenting with mothers

\section{Impact on other professionals}

The Growing Futures intervention aimed to influence the practice of other local practitioners through the DANs' involvement in joint work, training and mentoring sessions. There was consistent evidence in the learning logs of DANs challenging those practitioners who took blaming or uninformed approaches towards mothers experiencing DVA:

'[the new sw] seemed to be more able to listen to mother saying that she cannot be punished (take the children away) because he continues to break his bail conditions and enter the household. I feel that I helped empower mother to speak out in a respectful way in her defence.' (DAN)

The pilot's philosophy included a particular emphasis on training and encouraging other practitioners to use DVA risk assessment tools in their work and interviews with the four children's social workers who were trained as DANs revealed increased use of risk assessment in DVA cases: 
I've used the DASH risk assessment in one of my cases where I wouldn't have before (Social Worker DAN)

Evidence of other forms of change for children's social workers was more mixed. Social workers who had received DAN training had clearly benefited from the opportunities to undertake joint work with colleagues with expertise and skills in DVA:

I definitely feel like now when I get DV cases... I've got a structure in my mind of what I want to do with it, what I want to find out... I feel like it's going to improve my practice. (Social Worker DAN)

However, those social workers who were intended to undertake DAN work on a part-time basis failed to do so, seemingly because of the demands of their statutory case load. Some social workers appeared to value the DANs' input mainly in terms of the extent to which it freed them up to focus on other aspects of their caseload:

'what's made my job easier is [the DAN] doing all that work with the DVA... By them...doing that work with mum and that bit of therapeutic work with the kids, I've not had to look at that, which has freed us up to concentrate on other stuff.' (Social Worker)

Such comments argue the need for practitioners to have sufficient space and time in their workload to acquire and practice new skills and approaches.

\section{Impact on wider systems}

The 'whole system change' ambitions for the pilot - 'we're here to change people's views...on domestic abuse' (DAN) - entailed increased understanding and awareness of DVA's impact on families and the development of co-ordinated systems to strengthen the community and service response. Interviews with a small number of professionals from other services indicated that they had grasped the pilot's philosophy of whole family working and developed some commitment to it:

'Growing Futures've... really banged the desk on that one, you know, banged the table and said 'We've got to look beyond that [victim-focussed risk management], and try and put things right so the family if they wish to stay together can stay together'.

(Other Professional)

However, some of the other professionals consulted had misinterpreted the pilot's philosophy as a commitment to keeping families together in every instance.

Mixed views were expressed regarding shared understandings of referral paths for families experiencing DVA. While some other professionals reported increased clarity in this respect, others lacked understanding as to how standard and medium risk DVA cases should be progressed. A plan to introduce a common risk assessment tool across services was not realised in the course of the project's first 18 months.

While a range of views were expressed as to whether interagency communication on DVA cases had improved, there was general support for the development of a more collaborative working culture and joined-up approaches. In general, Growing Futures was seen to have made a positive start on shifting perceptions and practices: 
'I mean Rome wasn't built in a day, you're going to get pockets. But now there's more of a warmth, there's more of an openness, in terms of being able to do effective partnership work.' (Other professional)

\section{Discussion}

We noted above that 'whole family' models of intervention tend to differ according to which sector they spring from. The Growing Futures intervention had its raison d'etre and its roots in the failings of child care social work with families experiencing DVA. It aimed to develop and cascade a different sort of service, one that was characterised by partnership with families rather than confrontation and blame. The opportunity to undertake 'whole family' work in a flexible manner, to work with families on a non-statutory basis and to deploy a range of therapeutic tools to address the effects of DVA appears to have resonated with families, promoted engagement and built trust. DANs were enabled to work differently by a strong emphasis on the 'whole family' model and associated tools, limited caseloads and high levels of supervision and training. This approach gives credence to Mandel's (2014) arguments for the importance of an organisational framework that underpins and provides ongoing support for this type of work.

Families of course have different members who may be more or less detached from the family household and who experience power and control differently within the family. It was apparent that the DANs as a group were slower in developing confidence and skills in work with perpetrators than they were in work with mothers and children who were the traditional targets for their intervention. Direct work and work on parenting skills were less likely to happen with perpetrators than they were with mothers and children and DANs often referred perpetrators on to the specialist worker within the team or to the specialist perpetrators' service. This is unsurprising given that experience and skills in working with fathers are in short supply in children's social care. Child protection social work's levels of engagement with fathers who are perpetrators of DVA are reported to be low (Alaggia et al 2015; Stanley et al, 2011; Baynes and Holland 2010) and this has been attributed to a variety of factors including fathers' lack of enthusiasm for submitting themselves to the scrutiny of statutory services, their limited availability and intimidating behaviour as well as practitioner attitudes and fears for their safety (Humphreys and Absler, 2011). However, a focus on their role as fathers has been identified as a means of increasing men's recognition of and willingness to change abusive behaviour (Stanley, Graham-Kevan, and Borthwick, 2012) and this is the rationale for programmes such as Caring Dads that take men's parenting and DVA as their twin focus (McConnell et al 2014; McConnell, Barnard, Holdsworth, and Taylor, 2016).

Introducing the shift of focus that is required if fathers are to be part of 'whole family' work may require additional resource at the level of the face-to-face work with the family as well as organisational support. Much of the work with different family members undertaken by the DANs was done in pairs, either with their DAN colleagues or with children's social workers. This approach appeared to be helpful in enabling practitioners to take on different roles in relation to the family. Such roles included: 'good cop, bad cop'; children's and parents' advocates or men's and women's workers. It also offered opportunities for skills to be learnt 'by doing' as well as creating a space for joint reflection and review of practice.

Given the complexity of work with different family members whose experience of DVA and consequent needs may differ, there are strong arguments for practitioners to work in dyads with a family. This clearly has resource consequences but it is a key point for consideration if this approach 
is to be rolled out to children's social care more widely. 'Whole family' work in DVA is replete with potential pitfalls including the possibility of collusion with perpetrators (Iwi and Newman 2015), the capacity for escalating rather than reducing violence and a tendency for some family members to be excluded from interventions because too many conflicting perspectives cannot be contained by one worker. The inclusion of a second practitioner offers a reflexive sounding board which can mitigate these risks through a process of 'on the spot' case review and analysis.

Whilst social workers in Doncaster reported some indications of acquiring new skills in DVA work and increased use of risk assessment tools, at 18 months into the pilot, it did not appear as though the pilot had achieved a discernible shift away from them simply signposting DVA cases to other agencies. There seemed to be some way to go before they could assume ownership of the work themselves, particularly in relation to work with perpetrators.

\section{Conclusion}

The design and implementation of 'whole family' approaches for families living with DVA are as yet in the early stages of development. This model has arisen from confronting the reality that for some women and children, their lives may be no better following separation, or they are not in a position to separate. In the past, this has led to extensive mother-blaming with workers berating mothers for their 'failure to protect' children and such approaches have undermined practitioners' ability to work in partnership with families. Clearly, some women must separate from violent partners if they are not to be killed or suffer very significant harm. However, extensive unsupervised, court ordered contact with fathers who use violence has often placed children in the situation where they are the ones left unable to leave an abusive relationship. Finding ways to work with families who still wish to stay together but without violence, or pursue post-separation arrangements without violence is an on-going challenge.

In particular, the work of engaging with and working to change the behaviour of abusive fathers remains a high priority but the least developed intervention strategy. Other emerging models are exploring different approaches to this question and further evidence from such projects, particularly in respect of outcomes for families, would be welcome. The initiative described here offers an example of how, in a children's social care setting where additional resources and organisational support are made available, practice can be shifted away from a blaming approach to one that emphasises the potential for recovery and change for all family members.

\section{Acknowledgement}

The authors wish to acknowledge all those who contributed to the research including the Opcit research team led by Katie McCracken and Monica Campo, Australia Institute of Family Studies, as well as all research participants.

\section{References}

Alaggia, R., Shlonsky, A., Gadalla, T., Jenny, A., \& Daciuk, J. (2015) Does differential response make a difference: examining domestic violence cases in child protection services. Child and Family Social Work, 20(1), 83-95. 
Bancroft, L., and Silverman, J. (2011) The Batterer as Parent: Addressing the impact of domestic violence on family dynamics, $2^{\text {nd }}$ Edition. New York: Sage.

Barry, G. (2011).Domestic Homicide Review Cydney/2011: Overview Report. Kent Community Safety Partnership, Medway Community Safety Partnership.

Baynes, P., and Holland, S. (2012) Social work with violent men: a child protection file study in an English Local Authority. Child Abuse Review, 21, 53-65.

Blacklock, N., and Phillips, R. (2015) Reshaping the Child Protection Response to Domestic Violence through Collaborative Working, in Stanley, N., and Humphreys. C. (eds.) Domestic Violence and Protecting Children: New thinking and approaches. London: Jessica Kingsley, pp 196-212.

Blijf Groep (2011) The Oranje Huis Approach: A new style women's shelter in the Netherlands. Amsterdam: Stichtng Blijf Groep.

Braun, V., and Clarke, V. (2006) Using thematic analysis in psychology. Qualitative Research in Psychology, 3(2), 77-101.

Department for Education (2016) Characteristics of children in need: 2015 to 2016, National Statistics SFR 52/2016, 3 November 2016. Available at:

https://www.gov.uk/government/uploads/system/uploads/attachment data/file/564620/SFR522016 Main Text.pdf

Featherstone, B. (2009) Contemporary Fathering: Theory, Policy and Practice. Bristol: Policy Press.

Featherstone, B., and Peckover, S. (2007) 'Letting Them Get Away With It: Fathers, domestic violence and child welfare'. Critical Social Policy, 27 (2) 181-202.

Heward-Belle, S. (2016) The Diverse Fathering Practices of Men Who Perpetrate Domestic Violence, Australian Social Work, 69(3), 323-337.

Holt, S. (2015) Focusing on Fathering in the Context of Domestic Abuse: Children's and Fathers' Perspectives, in Stanley, N. and Humphreys. C. (eds.) Domestic Violence and Protecting Children: New thinking and approaches. London: Jessica Kingsley, pp 166-181.

Humphreys, C. and Absler, D. (2011) History repeating: child protection responses to domestic violence. Child and Family Social Work, 16, 369-489.

Humphreys, C. and Campo, M. (2017 forthcoming) Fathers who use violence: options for safe practice where there is ongoing contact with children. Issues Paper. Melbourne: Australian Institute of Family Studies.

Humphreys, C. and Stanley, N. (2017) Shifting the Focus: working differently with domestic violence in Connolly, M. (ed.) Beyond the Risk Paradigm: current debates and new directions. London: Macmillan Education, pp 147-160.

Hutchfield, J., and Coren, E. (2011) The Child's Voice in Service Evaluation: Ethical and Methodological Issues. Child Abuse Review, 20, 173-186.

Iwi, K. and Newman, C. (2015) Engaging with Perpetrators of Domestic Violence: Practical Techniques for Early Intervention. London: Jessica Kingsley Publishers 
Jannawi Family Centre (2015) Worker response to domestic violence and other violence Doc. Ref. No: 5-B12.

Jenkins, A. (2009) Becoming ethical: A parallel political journey with men who have abused. Lyme Regis: Russell House.

Jory, B., Anderson, D., \& Greer, C. (1997) Intimate justice: confronting issues of accountability, respect and freedom in treatment for abuse and violence. Journal of Marital and Family Therapy, 23, 399-415.

Kan M, Feinberg M. (2014) Can a family-focused, transition-to-parenthood program prevent parent and partner aggression among couples with young children? Violence and Victims, 29:967-80.

Keddell, E. (2014) Theorising the signs of safety approach to child protection social work: Positioning, codes and power. Children and Youth Services Review, 47(1), 70-77.

Kelly, L., and Westmarland, N. (2015) Domestic Violence Perpetrator Programmes: Steps Towards Change. London and Durham: London Metropolitan University and Durham University. https://www.dur.ac.uk/criva/projectmirabal

Kohn, L.S. (2010). What's so Funny about Peace, Love and Understanding? Restorative Justice as a New Paradigm for Domestic Violence Intervention. Seton Hall Law Review, 40 (2), 517595.

Kimball, E. (2016) Edleson Revisited: Reviewing Children's Witnessing of Domestic Violence 15 Years Later. Journal of Family Violence, 31, 625-637.

Lamb, M.E. (ed.) (2010) The Role of the Father in Child Development. $5^{\text {th }}$ Edition. Chichester: Wiley. Lapierre, S. (2010) 'Striving to be "Good" Mothers: Abused women's experiences of mothering'. Child Abuse Review, 19 (5) 342-357.

Leeds City Council (undated)

(http://springconsortium.com/wpcontent/uploads/2014/06/Storyboard-Leeds-City-Council.pdf

Maxwell, N., Scourfield, J., Holland, S., Featherstone, B., and Lee, J. (2012). The Benefits and Challenges of Training Child Protection Social Workers in Father Engagement. Child Abuse Review, 21: 299-310.

McConnell, N., Barnard, M., Holdsworth, T., and Taylor, J. (2014) Caring Dads: Safer children. Interim Evaluation Report. London: NSPCC.

McConnell, N., Barnard, M., Holdsworth, T. and Taylor, J. (2016). Caring Dads: Safer Children Evaluation Report. Evidence and Practice Series. London: NSPCC.

https://www.nspcc.org.uk/globalassets/documents/evaluation-of-services/caring-dads-saferchildren-evaluation-report.pdf

Mejdoubi, J., van den Heijkant, C. C. M., van Leerdam, F. J., Heymans, M. W., Hirasing, R. A., and Crijen, A. (2013) Effect of nurse home visits vs. usual care on reducing intimate partner violence in young high-risk pregnant women: a randomized controlled trial. PLOS One, 8(10), PMC3804627.

Morris, K., and Connolly, M. (2012) Family decision making in child welfare: challenges in developing a knowledge base for practice. Child Abuse Review, 21, 1, 41-52. 
Pennell, J., and Burford, G. (2002) Feminist praxis: Making family group conferencing work, in Strang, H., and Braithwaite, J. (eds.), Restorative justice and family violence. Cambridge: Cambridge University Press, pp. 108-127.

Radford, L. and Hester, M. (2015) More Than a Mirage? Safe Contact for Children and Young People Who Have Been Exposed to Domestic Violence, in Stanley, N. and Humphreys. C. (eds.) Domestic Violence and Protecting Children: New thinking and approaches. London: Jessica Kingsley, pp. 135-152.

Scourfield, J., Cheung, S. Y., and Macdonald, G. (2014) Working with fathers to improve children's well-being: Results of a survey exploring service provision and intervention approach in the UK. Children and Youth Services Review, 43, 40-50.

Sharps, P. W., Campbell, J., Baty, M. L., and Bair-Merrit, M. H. (2008) Current evidence on perinatal home visiting and intimate partner violence. Journal of Obstetrics Gynecology Neonatal Nursing, 37(4), 4880-4490.

Simpson, L., Gattis, K., Atkins, D., and Christensen, A. (2008) Low level relationship aggression and couple therapy outcomes. Journal of Family Psychology, 22, 102-111.

Stover, C. (2015) Fathers for change for substance use and intimate partner violence: Initial community pilot. Family Process, 54, 600-609.

Stanley, N. (2011) Children Experiencing Domestic Violence: A Research Review. Dartington: RIP.

Stanley, N., Miller, P., Richardson-Foster, H. and Thomson, G. (2011. A Stop-Start Response: Social Services' Interventions with Children and Families Notified Following Domestic Violence Incidents. British Journal of Social Work, 41, 2, 296-313.

Stanley, N., Graham-Kevan, N. and Borthwick, R. (2012) Fathers and Domestic Violence: building motivation for change through perpetrator programmes. Child Abuse Review 4, 264-274.

Stanley, N. (2015) Moving towards Integrated Domestic Violence Services for Children and Families Violence, in Stanley, N. and Humphreys. C. (eds.) Domestic Violence and Protecting Children: New thinking and approaches. London: Jessica Kingsley, pp. 239-254.

The Stephanou Foundation (2015) Healthy Relationships: Healthy Baby http://www.stefanoufoundation.org/hrhb. Accessed 30.3.2017

Turnell, A. and Edwards, S. (1999) Signs of Safety: A Solution and Safety Oriented Approach to Child Protection Casework, London: W.W. Norton and Company. 
Table 1 DANs' engagement with 102 families, April 2015-Sept 2016

\begin{tabular}{|c|c|c|}
\hline Family Members & On caseload & Engaged in direct work \\
\hline Children \& young people & 232 & $153(66 \%)$ \\
\hline Victims & 102 & $72(71 \%)$ \\
\hline Perpetrators & 90 & $49(54 \%)$ \\
\hline Other Family members & 16 & $3(19 \%)$ \\
\hline Total & 440 & $277(63 \%)$ \\
\hline
\end{tabular}

